\title{
Evaluation of iron replacement therapy efficiency using a complex panel of biomarkers
}

\author{
Sándor Pál ${ }^{1}$, Zsuzsanna Faust ${ }^{1 *}$, Barbara Réger ${ }^{2}$, Attila Miseta $^{2}$, Margit Varjú- \\ Solymár ${ }^{1}$, Enikő Nemes-Nagy ${ }^{3}$, Mariana Cornelia Tilinca $^{4}$, Hussain Alizadeh ${ }^{5}$ \\ 1. Department of Laboratory Medicine, Department of Transfusion Medicine, University of Pécs - \\ Clinical Centre, Hungary
}

2. Department of Laboratory Medicine, University of Pécs - Clinical Centre, Hungary

3. Department of Chemistry and Medical Biochemistry, "George Emil Palade" University of Medicine,

Pharmacy, Science and Technology of Targu Mures,, Romania

4. Department of Internal Medicine 1, Romania, "George Emil Palade” University of Medicine,

Pharmacy, Science and Technology of Targu Mures,, Romania

5. 1st. Department of Internal Medicine, Division of Hematology, University of Pécs - Clinical Centre, Hungary

Received: $8^{\text {th }}$ October 2021; Accepted: $10^{\text {th }}$ January 2022; Published: $13^{\text {th }}$ January 2022

World Health Organization (WHO) defines anemia as a hemoglobin $(\mathrm{Hb})$ concentration lower than $12 \mathrm{~g} / \mathrm{dL}$ in women and $13 \mathrm{~g} / \mathrm{dL}$ in men, respectively. The WHO classification of anemia severity by hemoglobin concentration is presented in table $1(1,2)$. The most significant proportion of anemia types is related to nutritional deficiencies, iron deficiency being identified as the most frequent etiology (3). According to a population-representative study by Kassebaum et al. during the 1990-2010 period, the global prevalence of anemia and iron deficiency anemia has shown a decreasing tendency, although it remained significantly high. In 2010 the prevalence of anemia was approximately $33 \%$, iron deficiency being the most frequently identified underlying etiology. In the same study, iron deficiency was revealed in $20 \%$ of women with no recorded past medical history (4).

Optimal anemia correction is closely related to the identification of the etiology of the underlying condition or disease. Recommended laboratory parameters include complete blood count with detailed erythroid parameters, mean corpuscular volume (MCV), mean corpuscular hemoglobin $(\mathrm{MCH})$, red cell distribution width (RDW) and absolute reticulocyte (Ret) number. The laboratory assessment of iron metabolism is of paramount importance. The most widely used laboratory parameters are serum iron-(Se-Fe),

\footnotetext{
* Corresponding author: Zsuzsanna Faust, epartment of Laboratory Medicine, Department of Transfusion Medicine, University of Pécs - Clinical Centre, Ifjúság str. 13, 7624, Pécs, Hungary. E-mail: faust.zsuzsanna@pte.hu
} 
ferritin-(F), transferrin- (Tfr), and soluble transferrin-receptor (sTfR) concentration, transferrin saturation (Tfr-sat) and soluble transferrin-receptor/logferritin index ( $\mathrm{sTfR} / \log \mathrm{F})$ index. (The reference intervals are represented in table 2) (57). As inflammatory processes highly influence iron metabolism, quantitative analysis of C-reactive protein (CRP) is also an element of laboratory investigation (Table 3 ). Follow-up laboratory examinations are used for therapy effectiveness evaluation. Iron homeostasis can also be evaluated by laboratory assessment of hepcidin. Hepcidin can be determined from urine and blood samples and may give useful information about iron-homeostasis, but it is not routinely used in clinical practice (8-10).

Accurate and rapid diagnosis of iron deficiency anemia is significant in order to reduce red blood cell transfusion likelihood. Additionally, preope- rative anemia represents an independent risk factor for increased postoperative morbidity and mortality in cases of elective surgical interventions (13-15).

Appropriate selection of iron replenishment therapy modalities is frequently influenced by numerous factors, comorbidities and anemia severity. The algorithm of iron replacement, considering the costs and simplicity of the treatment, begins with oral iron substitution. The gastrointestinal side effects of these products (especially those containing iron-sulphate), intolerance, allergic reactions, and adverse reactions contribute to reducing the patients' compliance, thereby the treatment efficacy (16). Oral iron replenishment therapy ineffectiveness is often related to an underlying, undiagnosed malabsorptive disease, such as inflammatory bowel diseases (IBD) (Crohn's disease, ulcerative colitis), celiac di-

Table 1. WHO classification of anemia severity considering hemoglobin concentrations in adult male and female population

\begin{tabular}{lll}
\hline Anemia severity & Women & Men \\
\hline Mild & $11-12 \mathrm{~g} / \mathrm{dL}$ hemoglobin & $11-13 \mathrm{~g} / \mathrm{dL}$ hemoglobin \\
\hline Moderate & $8-11 \mathrm{~g} / \mathrm{dL}$ hemoglobin & \\
\hline Severe & $<8 \mathrm{~g} / \mathrm{dL}$ hemoglobin & \\
\hline
\end{tabular}

Table 2. Reference intervals of parameters utilised for laboratory diagnosis of iron deficiency anemia

\begin{tabular}{|c|c|c|c|}
\hline Parameter & Unit of measure & Women & Men \\
\hline RBC & $\mathrm{T} / \mathrm{L}$ & $3.9-5.3$ & $4.5-6.0$ \\
\hline WBC & $\mathrm{G} / \mathrm{L}$ & \multicolumn{2}{|c|}{$4-10$} \\
\hline $\mathrm{Hb}$ & $\mathrm{g} / \mathrm{L}$ & $120-157$ & $137-175$ \\
\hline Htc & $\%$ & $34.1-44.9$ & $40.1-51.0$ \\
\hline$\overline{\mathrm{MCV}}$ & $\mathrm{fL}$ & \multicolumn{2}{|c|}{$88-95$} \\
\hline $\mathrm{MCH}$ & pg & \multicolumn{2}{|c|}{$26-33$} \\
\hline RDW & $\%$ & \multicolumn{2}{|c|}{$11.6-14.4$} \\
\hline Ret & $\mathrm{G} / \mathrm{L}$ & \multicolumn{2}{|c|}{$25-75$} \\
\hline Se-Fe & $\mu \mathrm{mol} / \mathrm{L}$ & $6.6-26$ & $7.0-28.3$ \\
\hline Transferrin & $\mathrm{g} / \mathrm{L}$ & \multicolumn{2}{|c|}{$2.0-3.6$} \\
\hline Trf-sat & $\%$ & \multicolumn{2}{|c|}{$16-45$} \\
\hline Ferritin & $\mu \mathrm{g} / \mathrm{L}$ & $13-150$ & $30-400$ \\
\hline sTfR & $\mathrm{mg} / \mathrm{L}$ & $1.9-4.4$ & $2.2-5.0$ \\
\hline CRP & $\mathrm{mg} / \mathrm{L}$ & \multicolumn{2}{|c|}{$<5$} \\
\hline
\end{tabular}


Table 3. Relevance and characteristics of laboratory parameters used for iron deficiency anemia diagnosis $(11,12)$

\begin{tabular}{|c|c|c|}
\hline Parameter & Importance & Iron deficiency anemia \\
\hline Hemoglobin (g/dL) & Anemia diagnosis & $<13$ (men), $<12$ (women) \\
\hline MCV, MCH & $\begin{array}{l}\text { Size and hemoglobin concentration of red blood } \\
\text { cell refers to anemia etiology }\end{array}$ & Hypochromic, microcytic \\
\hline Ferritin & $\begin{array}{l}\text { Assessment of iron storage, positive acute phase } \\
\text { protein }\end{array}$ & Low, excepting inflammation \\
\hline Serum-iron & $\begin{array}{l}\text { Low value in case of anemia diagnosis, except- } \\
\text { ing hemochromatosis and iron intoxication }\end{array}$ & $\begin{array}{l}\text { Low, significant fluctuations may } \\
\text { be present }\end{array}$ \\
\hline Transferrin & $\begin{array}{l}\text { Iron transport protein, negative acute phase pro- } \\
\text { tein }\end{array}$ & High, excepting inflammation \\
\hline Transferrin-saturation & Rate of transferrin saturated with iron & $\begin{array}{l}\text { Generally low, not specific for iron } \\
\text { deficiency }\end{array}$ \\
\hline sTfR & $\begin{array}{l}\text { Protein derived from precursor cells, and is } \\
\text { up-regulated in case of functional iron deficiency }\end{array}$ & Increased \\
\hline sTfR-logferritin index & $\begin{array}{l}\text { Rate of sTfR and log ferritin, one of the most } \\
\text { sensitive and most specific parameter of iron de- } \\
\text { ficiency anemia diagnosis }(9,10)\end{array}$ & Increased \\
\hline
\end{tabular}

sease, gastrointestinal parasitosis or eventually gastrointestinal blood loss. Rare inherited genetic disorders should also be considered to hinder oral iron replenishment treatment (SLC11A2-, TMPRSS6- mutations) (17). According to the latest guidelines, parenteral iron treatment can only be initiated after the proven ineffectiveness of oral substances and/or in case of intolerance to oral preparations. Exceptions are represented by cases of iron malabsorption, for instance, different forms of IBD, post-bariatric surgical intervention status, in which oral iron treatment is rarely effective, moreover, it can sometimes enhance disease activity (18). In these situations, parenteral iron substitution is the first-choice treatment for iron deficiency anemia. Intravenous iron therapy is sometimes considered as a nonpopular treatment option for iron deficiency (19). However, clinical evidence suggests the opposite, particularly in the case of novel products. Nevertheless, this attitude is still present primarily due to the fear of adverse side effects associated with older products (20). Ferric-carboximaltose (FCM) is a stable, complex molecule and a relatively new parenteral iron product with a favourable safety profile (21). The advantage of FCM is its ability to replace large quantities of iron, offering a faster resolution for iron deficiency or iron deficiency anemia compared to other parenteral and oral formulations (22) (23). Evidence shows that it is effective for the treatment of iron deficiency anemia related to IBD, chronic heart failure, chronic kidney disease (dialysis-dependent and dialysis independent), and pregnancy (21).

Sodium ferric gluconate complex (SFGC) is a parenteral iron substance with a safe side effect profile, but it requires repeated administrations. Its safety and efficacy for treating functional iron deficiency and iron deficiency anemia related to chronic kidney failure and chronic heart failure have been proven in numerous studies $(24,25)$. Both SFGC and FCM have more favourable side effect profiles than older, iron-dextran type parenteral substances (26).

The applicability of iron replenishment therapy is not limited to the correction of iron deficiency anemia. Khallafallah et al., in a clinical trial, demonstrated that perioperative parenteral iron 
replacement therapy of functional iron deficiency significantly improved postoperative morbidity and mortality (27).

Our aim included the assessment of iron metabolism and the clinical efficacy of FCM and SFGC. Our cross-sectional study evaluated the laboratory results of 59 patients between 2017.01.01 and 2020.08.31, at the Division of Hematology of the 1st. Department of Internal Medicine, University of Pécs-Hungary. All of the included patients have been receiving parenteral iron therapy. Our patients were treated with two different types of intravenous iron substances (FCM and SFGC). Blood sample collection was performed at the initial presentation and at predefined regular post-infusion intervals, usually between four to six weeks after the treatment. The study has been approved by the Department of Data Protection, Equality and Coordination, University of Pécs (KK/724-2/2020).

Blood samples were collected by peripheral venipuncture in Vacutainer test tubes (Becton Dickinson). For blood count, test tubes of $3 \mathrm{ml}$ were used, containing $5.4 \mathrm{mg}$ K2-EDTA. Sample analyses were performed on Sysmex XN 2000 hematological analyser within 2 hours from blood sample collection. The following parameters were determined: white blood cell (WBC), absolute neutrophil-, eosinophil-, basophil granulocyte, lymphocyte, monocyte number and proportion, red blood cell (RBC) number, hemoglobin $(\mathrm{Hb})$, hematocrit $(\mathrm{Ht})$, mean corpuscular volume (MCV), mean hemoglobin concentration $(\mathrm{MCH})$, mean corpuscular hemoglobin concentration (MCHC), red cell distribution width (RDW), platelet count (PLT), absolute reticulocyte count, peripheral blood smear. Whole blood samples had also been collected for biochemical analyses: serum-iron (Se-Fe), transferrin-, ferritin-, and soluble transferrin receptor concentration, transferrin-saturation, and CRP. Biochemical analyses were performed on
Roche Cobas analyser, using Roche (Roche, Basel, Switzerland) reagent. Reference intervals are represented in table 2.

Data analysis was performed using Microsoft Office ExcelTM and SPSS 20. Paired samples t-test was used for comparison of laboratory parameters with normal distribution and Mann-Whitney test was performed for not normally distributed parameters (F, CRP, sTfR/logF index) before iron replacement therapy and at follow-up investigation.

The mean age of the investigated subjects was $50.34+/-14.61$ (SD) years, $87.9 \%$ of them being females. Our patients presented the following underlying diseases: IBD (7/59), myoma (3/59), malabsorption syndrome (3/59), gastroesophageal reflux disease $(3 / 59)$, chronic heart failure (2/59), occult bleeding (2/59), chronic kidney disease (1/59), Osler syndrome (1/59), hemorrhoids (1/59) and mucosa-associated lymphoid tissue lymphoma (1/59). Other diseases were also present, which are possibly not related to the development of iron deficiency anemia: hypertension (4/59), diabetes mellitus (2/59), and thyroid disease (2/59). In 24/59 of the cases, further investigations are necessary to clarify the underlying condition of iron deficiency anemia. $12 / 59$ of our patients were treated with a mean dose of $528 \mathrm{mg}$ parenteral SFGC, in an average of 5.28 days compared to those receiving a mean dose of $602 \mathrm{mg}$ parenteral FCM treatment over 30-45 minutes.

Comparing the patients' laboratory parameters (prior to treatment vs follow-up examination), there was no statistically significant difference between CRP $(p=0.076)$, WBC $(p=0.837)$ and Ret $(p=0.711)$. We observed a statistically significant increase of mean $\mathrm{Hb}$ concentration $(\mathrm{p}<0.0001), \mathrm{MCV}(\mathrm{p}<0.0001), \mathrm{MCH}(\mathrm{p}<0.0001)$ $\mathrm{F}(\mathrm{p}<0.0001)$ and Trf-sat $(\mathrm{p}<0.0001)$, values at the follow-up laboratory testing. Furthermore, a statistically significant decrease of $\operatorname{Trf}$ 
$(\mathrm{p}<0.0001)$ and sTfR $(\mathrm{p}<0.0001)$ could also be observed (detailed statistical analysis is represented in Table 4). sTfR/logF index values have shown a statistically significant $(\mathrm{p}<0.0001)$ reduction at the moment of follow-up testing. Iron deficiency is related to numerous underlying diseases such as heart failure, chronic kidney disease, chronic blood loss, inflammatory bowel diseases, pulmonary arterial hypertension etc. (28) Therefore, the diagnostic algorithm of iron deficiency anemia is not limited to laboratory analyses (29). Detailed history, physical examination, radiological and other imaging examinations are essential elements of the diagnostic algorithm used to identify the underlying condition rapidly. For the diagnosis of iron deficiency, laboratory assessment of iron metabolism is of paramount importance $(19,30)$.

Primary treatment of anemia is based on the underlying etiology, aiming to treat the underlying disease (31). For optimal results, oral iron replacement therapy should be initiated following the diagnosis of the underlying condition. The duration of iron replenishment with oral substances and the frequent gastrointestinal side effects (reflux-disease, constipation) and intolerance, allergies, or adverse reactions reduce the patients'compliance. Therefore, a lack of therapy effectiveness is common $(17,32)$. In addition, the patient must be informed about the etiology of iron deficiency, the available treatment options, the expected effectiveness of the planned

Table 4. Detailed statistical analysis of the measured parameters

\begin{tabular}{|c|c|c|c|c|c|c|c|c|c|}
\hline \multicolumn{4}{|c|}{$\begin{array}{l}\text { At the time of follow-up } \\
\text { laboratory assessment }\end{array}$} & \multicolumn{3}{|c|}{$\begin{array}{l}\text { At the time of parenteral } \\
\text { iron therapy }\end{array}$} & \multicolumn{3}{|c|}{$\begin{array}{c}\text { Statistical comparison (paired sam- } \\
\text { ples t-test) }\end{array}$} \\
\hline Parameter & Mean & \multicolumn{2}{|c|}{$\begin{array}{l}\text { Standard } \\
\text { deviation }\end{array}$} & Mean & \multicolumn{2}{|c|}{$\begin{array}{l}\text { Standard } \\
\text { deviation }\end{array}$} & p-value & $\begin{array}{c}\text { lower } \\
95 \% \mathrm{CI} \\
\text { of the } \\
\text { difference }\end{array}$ & $\begin{array}{c}\text { upper } \\
95 \% \mathrm{CI} \text { of } \\
\text { the } \\
\text { difference }\end{array}$ \\
\hline WBC & 6.32 & \multicolumn{2}{|c|}{2.35} & 6.262 & \multicolumn{2}{|c|}{1.89} & .837 & -0.520 & 0.639 \\
\hline $\mathrm{RBC}$ & 4.15 & \multicolumn{2}{|c|}{0.62} & 4.58 & \multicolumn{2}{|c|}{0.57} & .000 & -0.56 & -0.29 \\
\hline PLT & 345.66 & \multicolumn{2}{|c|}{134.80} & 297.25 & \multicolumn{2}{|c|}{112.54} & .002 & 19.45 & 77.36 \\
\hline $\mathrm{Hb}$ & 91.66 & \multicolumn{2}{|c|}{13.12} & 114.58 & \multicolumn{2}{|c|}{17.20} & .000 & -27.35 & -18.48 \\
\hline Htc & 29.08 & \multicolumn{2}{|c|}{5.19} & 35.83 & \multicolumn{2}{|c|}{4.63} & .000 & -8.51 & -4.99 \\
\hline $\mathrm{MCV}$ & 72.76 & \multicolumn{2}{|c|}{8.86} & 78.41 & \multicolumn{2}{|c|}{6.47} & .000 & -7.45 & -3.85 \\
\hline $\mathrm{MCH}$ & 22.39 & \multicolumn{2}{|c|}{3.53} & 25.11 & \multicolumn{2}{|c|}{3.11} & .000 & -3.38 & -2.05 \\
\hline RDW & 18.19 & \multicolumn{2}{|c|}{3.37} & 20.47 & \multicolumn{2}{|c|}{5.03} & .001 & -3.52 & -1.04 \\
\hline Ret & 51.57 & \multicolumn{2}{|c|}{25.23} & 55.48 & \multicolumn{2}{|c|}{43.45} & .711 & -25.61 & 17.80 \\
\hline $\mathrm{Se}-\mathrm{Fe}$ & 4.18 & \multicolumn{2}{|c|}{1.88} & 9.26 & \multicolumn{2}{|c|}{5.57} & .000 & -7.08 & -3.08 \\
\hline Trf & 3.49 & \multicolumn{2}{|c|}{0.64} & 3.04 & \multicolumn{2}{|c|}{0.64} & .000 & 0.26 & 0.64 \\
\hline TrF-sat & 4.87 & \multicolumn{2}{|c|}{2.44} & 14.17 & \multicolumn{2}{|c|}{8.54} & .000 & -13.03 & -5.56 \\
\hline sTfR & 12.30 & \multicolumn{2}{|c|}{5.88} & 6.61 & \multicolumn{2}{|c|}{3.75} & .000 & 3.74 & 7.63 \\
\hline \multicolumn{4}{|c|}{$\begin{array}{l}\text { At the time of follow-up laboratory } \\
\text { assessment }\end{array}$} & \multicolumn{3}{|c|}{$\begin{array}{l}\text { At the time of parenteral } \\
\text { iron therapy }\end{array}$} & \multicolumn{3}{|c|}{$\begin{array}{l}\text { Statistical comparison } \\
\text { (Mann Whitney U test) }\end{array}$} \\
\hline & Median & Min & Max & Median & Min & Max & p-valu & e and Mann V & hitney's U \\
\hline $\mathrm{F}$ & 52.44 & 2 & 240 & 32.88 & 2 & 347 & & $\mathrm{p}<0.0001 ; 1$ & \\
\hline CRP & 4.06 & 0.3 & 81.6 & 7.59 & 0.20 & 62.10 & & $\mathrm{p}=0.076 ; \quad 3$ & \\
\hline sTfR/logF index & 0.97 & 0.02 & 9.72 & 2.75 & 0.02 & 14.47 & & $\mathrm{p}<0.0001 ; 8$ & 00 \\
\hline
\end{tabular}


treatment, safety, duration, and the possible side effects. Appropriate patient education is proven to raise patient compliance (23) and facilitates the detection of eventual therapy ineffectiveness, ensuring the best possible patient care.

Parenteral iron treatment is initiated when oral substances are contraindicated. Moreover, oral iron therapy is ineffective in case of underlying malabsorptive diseases such as IBD. Therefore in such cases, parenteral iron therapy is the first choice of treatment (17). Chronic kidney disease is often associated with anemia, especially caused by low erythropoietin level (33). In such cases, erythropoietin stimulating agents (ESA) are used in combination with iron to treat anaemia, and this combination usually improves the clinical outcomes. Palmer et al., in a meta-analysis, studied the effects of ESA and iron replacement therapy in chronic kidney disease. Their results suggested that the combination treatment was effective in transfusion avoidance in this population (34).

Subjects with pulmonary arterial hypertension (PAH) represent another category of patients who are frequently diagnosed with iron defficiency. In these patients, the oral substitutive therapy can lead to gastrointestinal side effects. To avoid this inconvenience, the parenteral iron administration with FCM is preferred in order to increase the efficiency of the treatment. Improvement of the anemia and of the iron status is correlated with the medium and long-term survival of idiopathic PAH patients. (35) Ponikowski et al., demonstrated a significantly reduced risk of hospitalization due to worsening heart failure in patients treated with FCM, as well as an improvement in their quality of life. (36).

Our retrospective study aimed to assess the efficacy of parenteral iron treatment and its effect on the quality of patient care. Our results indicate that intravenously administered iron replenishment therapy significantly improves the patients' erythroid parameters. We obtained a mean inc- rease of circulating hemoglobin concentrations with approximately $25 \mathrm{~g} / \mathrm{dl}$, equivalent to the effect of transfusion using two packed red blood cell units (37). Ht levels, as well as MCV and $\mathrm{MCH}$ parameters, were also significantly improved at follow-up, thus the beneficial effect of the treatment could be demonstrated. Additional laboratory assessment of the iron metabolism showed that a considerably improved iron status had been accomplished. Ferritin concentrations gained a five-fold increase at the time of follow-up (four to six weeks after iron replacement). A significant four-fold increase of transferrin-saturation could also be observed. Relying only on ferritin and transferrin-saturation in evaluating iron replacement effectiveness is insufficient since these parameters rapidly change during an inflammatory process (38). Therefore, sTfR concentration was also determined, especially in an underlying inflammatory disease. A significant reduction of sTfR could also be noticed. However, sTfR concentrations remained above the upper limit of the reference interval. These findings indicate that iron replenishment has been effective, although, a continuation of iron replacement is necessary for the patients whose sTfR concentrations remained above the reference interval.

Limitations of our retrospective study are the low number of included subjects and the heterogeneity of the underlying diseases. In addition, prospective observational studies would be necessary to obtain better quality information regarding the safety and effectiveness of intravenous iron replacement treatment. Nevertheless, our results indicate that the obtained improvements in laboratory parameters are comparable with the available speciality literature data $(25,27)$. Accordingly, considering the cost-effectiveness, side effect profile, and the patient's convenience, FCM is more advantageous than the other available parenteral iron replacement products (25). According to our findings, novel parenteral iron 
replacement substances are efficient, have favorable safety profile, and are cost-effective. However, further studies would be necessary to assess the effectiveness of these treatments for the underlying conditions independently.

\author{
Abbreviations \\ WHO - World Health Organization \\ $\mathrm{Hb}$ - Hemoglobin \\ MCV - mean corpuscular volume \\ $\mathrm{MCH}$ - mean corpuscular hemoglobin \\ $\mathrm{MCHC}$ - mean corpuscular hemoglobin concen- \\ tration \\ RDW - red cell distribution width \\ Ret - reticulocyte \\ $\mathrm{Se}-\mathrm{Fe}$ - serum iron \\ $\mathrm{F}$ - ferritin \\ Trf - transferrin \\ Trf-Sat - transferrin saturation \\ sTfR - soluble transferrin receptor \\ $\mathrm{sTfR} / \log \mathrm{F}$ - soluble transferrin receptor logfer- \\ ritin \\ CRP - C-reactive protein \\ IBD - inflammatory bowel disease \\ FCM - ferric-carboxymaltose \\ SFGC - sodium ferric gluconate complex \\ WBC - white blood cell \\ Ht - hematocrit \\ PLT - platelet \\ ESA - erythropoetin stimulating agent \\ $\mathrm{PAH}$ - pulmonary arterial hypertension
}

\section{Acknowledgements}

This publication was not financially supported.

\section{Authors' contribution}

All authors have prepared this manuscript and approved the submission and publication of this manuscript.

\section{Conflict of interest}

The authors declare no conflict of interest.

\section{References}

1. Marton I, Agócs S, Babik B. Az anaemiák epidemiológiája. [Epidemiology of anemia]. Orv Hetil. 2020;161(37):1569-73. DOI: 10.1556/650.2020.31916

2. FAO, WHO. World Declaration and Plan of Action for Nutrition. International Conference on Nutrition. Rome, Food and Agriculture Organization of the United Nations, December 1992.

3. McLean E, Cogswell M, Egli I, de Benoist B. Worldwide prevalence of anaemia 1993-2005: WHO global database on anaemia. Geneva, Switzerland World Health Organization. 2008.

4. Kassebaum NJ, Jasrasaria R, Naghavi M, WukIf SK, Johns N, Lozano $\mathrm{R}$ et al. A systematic analysis of global anemia burden from 1990 to 2010. Blood. 1990;123(5):615-24. DOI: 10.1182/ blood-2013-06-508325

5. Thomas DW, Hinchliffe RF, Briggs C, Macdougall IC, Littlewood T, Cavill I. Guideline for the laboratory diagnosis of functional iron deficiency. Br J Haematol. 2013;161(5):639-48. DOI: 10.1111/bjh.12311

6. Oustamanolakis P, Koutroubakis IE, Messaritakis I, Niniraki M, Kouroumalis EA. Soluble transferrin receptor-ferritin index in the evaluation of anemia in inflammatory bowel disease: a case-control study. Ann Gastroenterol. 2011;24(2):108-14.

7. Tijanić I, Vučić M, Golubovic LM. The significance of soluble transferrin receptors in diagnosing iron deficiency anemia. Rev Romana Med Lab. 2015;23(3):27583. DOI: $10.1515 / \mathrm{rrlm}-2015-0030$

8. Malyszko J, Malyszko JS, Matuszkiewicz-Rowinska J. Hepcidin as a therapeutic target for anemia and inflammation associated with chronic kidney disease. Expert Opin Ther Targets. 2019;23(5):407-21. DOI: 10.1080/14728222.2019.1599358

9. Nakanishi T, Kimura T, Kuragano T. The Hepcidin-Anemia Axis: Pathogenesis of Anemia in Chronic Kidney Disease. Contrib Nephrol 2019;198:124-34. DOI: 10.1159/000496636

10. Miseta A, Nagy J, Nagy T, Poór VS, Fekete Zs, Sipos K. Hepcidin and its potential clinical utility. Cell Biol Int. 2015;39(11):1191-202. DOI: 10.1002/cbin.10505

11. Van Den Bossche J, Devreese K, Malfait R, Van de Vyvere $\mathrm{M}$, Wauters A, Neeis $\mathrm{H}$, et al. Reference Intervals for a Complete Blood Count Determined on different Automated Haematology Analysers: Abx Pentra 120 Retic, Coulter Gen-S, Sysmex SE 9500, Abbott Cell 
Dyn 4000 and Bayer Advia 120. 2002;40(1):69-73. DOI: $10.1515 /$ CCLM.2002.014

12. Weiss G, Goodnough LT. Anemia of chronic disease. N Engl J Med. 2005;352(10):1011-23. DOI: 10.1056/ NEJMra041809

13. Camaschella C. Iron-deficiency anemia. N Engl J Med. 2015;372:1832-43. DOI: 10.1056/NEJMra1401038

14. Hempel E V., Bollard ER. The Evidence-Based Evaluation of Iron Deficiency Anemia. Med Clin North Am. 2016;100(5):1065-75. DOI: 10.1016/j. mena.2016.04.015

15. Retteghy TA. A vértakarékos betegellátás a perioperatív szakban. [Perioperative Patient Blood Management]. Hematológia-Transzfuziológia. 2018;51(4):194-203. DOI: 10.1556/2068.2018.51.4.4

16. Tolkien Z, Stecher L, Mander AP, Pereira DIA, Powell JJ, Ferrous sulfate supplementation causes significant gastrointestinal side-effects in adults: A systematic review and meta-analysis. PLoS ONE. Public Library of Science; 2015;10(2):e0117383. DOI: 10.1371/journal. pone. 0117383

17. Kloss-Brandstätter A, Erhart G, Lamina C, Meister B, Haun $\mathrm{M}$, Coassin $\mathrm{S}$, et al. Candidate gene sequencing of SLC11A2 and TMPRSS6 in a family with severe anaemia: common SNPs, rare haplotypes, no causative mutation. PLoS One. 2012;7(4):e35015. DOI: 10.1371/ journal.pone. 0035015

18. Gasché C, Dejaco C, Waldhoer T, Tillinger W, Reinisch W, Fueger GF, et al. Intravenous iron and erythropoietin for anemia associated with Crohn disease: A randomised, controlled trial. Ann Intern Med. 1997;126(10):782-7. DOI: 10.7326/0003-4819-12610-199705150-00006

19. Auerbach M, Adamson JW. How we diagnose and treat iron deficiency anemia. Am J Hematol. 2016;91(1):318. DOI: $10.1002 /$ ajh.24201

20. Auerbach M, Ballard H, Glaspy J. Clinical update: intravenous iron for anaemia. The Lancet, 2007;369(9572):1502-4. DOI: $10.1016 / \mathrm{S} 0140-$ 6736(07)60689-8

21. Geisser P, Banké-Bochita J. Pharmacokinetics, safety and tolerability of intravenous ferric carboxymaltose: a dose-escalation study in volunteers with mild iron-deficiency anaemia. Arzneimittelforschung. 2010;60(6 a):362-72. DOI: 10.1055/s-0031-1296301

22. Mu-oz M, Gómez-Ramírez S, Bhandari S. The safety of available treatment options for iron-deficiency ane- mia, Expert Opin Drug Saf, 2018; 17(2):149-59. DOI: 10.1080/14740338.2018.1400009

23. Breymann C, Gliga F, Bejenariu C, Strizhova N. Comparative efficacy and safety of intravenous ferric carboxymaltose in the treatment of postpartum iron deficiency anemia. Int J Gynecol Obstet. 2008;101(1):6773. DOI: $10.1016 /$ j.ijgo.2007.10.009

24. Coyne DW, Adkinson FN, Nissenson AR, Fishbane S, Agarwal R, Eschbach JW, et al. Sodium ferric gluconate complex in hemodialysis patients. II. Adverse reactions in iron dextran-sensitive and dextran-tolerant patients. Kidney Int. 2003;63(1):217-24. DOI: 10.1046/j.15231755.2003.00703.x

25. Eche IM, Owen KL, Eche IJ, Patel P, Sabe M. Safety and Effectiveness of an Accelerated Intravenous Iron Administration Protocol in Hospitalised Patients With Heart Failure. J Cardiovasc Pharmacol Ther. 2021;26(4):365-70. DOI: 10.1177/1074248421989871

26. Hussain I, Bhoyroo J, Butcher A, Koch TA He A, Bregman DB. Direct comparison of the safety and efficacy of ferric carboxymaltose versus iron dextran in patients with iron deficiency anemia. Anemia. 2013;2013:169107. DOI: 10.1155/2013/169107

27. Khalafallah AA, Yan C, Al-Badri R, Robinson E, Kirkby $\mathrm{BE}$, Ingram $\mathrm{E}$, et al. Intravenous ferric carboxymaltose versus standard care in the management of postoperative anaemia: a prospective, open-label, randomised controlled trial. Lancet Haematol. 2016;3(9):e415-25. DOI: 10.1016/S2352-3026(16)30078-3

28. Van Empel VP, Lee J, Williams TJ, Kaye DM. Iron deficiency in patients with idiopathic pulmonary arterial hypertension. Heart Lung Circ. 2014;23(3):287-92. DOI: 10.1016/j.hlc.2013.08.007

29. Powers JM, Buchanan GR. Diagnosis and Management of Iron Deficiency Anemia. Hematol Oncol Clin North Am. 2014;28(4):729-45. DOI: 10.1016/j. hoc.2014.04.007

30. Johnson Wimbley TD, Graham DY. Diagnosis and management of iron deficiency anemia in the 21st century. Therap Adv Gastroenterol. 2011;4(3):177-84. DOI: $10.1177 / 1756283 X 11398736$

31. Price EA, Mehra R, Holmes TH, Schrier SL. Anemia in older persons: Etiology and evaluation. Blood Cells Mol Dis. 2011;46(2):159-65. DOI: 10.1016/j. bemd.2010.11.004

32. Baird-Gunning J, Bromley J. Correcting iron deficiency. Aust Prescr. 2016;39(6):193-9. DOI: 10.18773/aust- 
prescr.2016.069

33. IV. NKF-K/DOQI clinical practice guidelines for anemia of chronic kidney disease: Update 2000. Am J Kidney Dis; 2001;37(1 Suppl 1):182-238. DOI: 10.1016/ S0272-6386(01)70008-X

34. Palmer SC, Saglimbene V, Mavridis D, Salanti G, Craig JC, Tonelli M, et al. Erythropoiesis-stimulating agents for anaemia in adults with chronic kidney disease: a network meta-analysis. Cochrane Database Syst Rev. 2014;12:CD010590. DOI: 10.1002/14651858. CD010590.pub2

35. Tilea I, Petra DN, Serban RC, Gabor MR, Tilinca MC, Azamfirei L., et al. Short-term impact of iron deficiency in different subsets of patients with precapillary pulmonary hypertension from an Eastern European pulmonary hypertension referral center, Int J Gen Med, 2021;14:3355-66. DOI: 10.2147/IJGM.S318343
36. Ponikowski P, van Veldhuisen DJ, Comin-Colet J, Ertl G, Komajda M, Mareev V, et al. CONFIRMHF Investigators. Beneficial effects of long-term intravenous iron therapy with ferric carboxymaltose in patients with symptomatic heart failure and iron deficiency. Eur Heart J. 2015;36(11):657-68. DOI: 10.1093/eurheartj/ ehu385

37. A. M. Naidech, M. J. Kahn, W. Soong, Green D, Hunt Batjer H, Bleck TP. Packed Red Blood Cell Transfusion Causes Greater Hemoglobin Rise at a Lower Starting Hemoglobin in Patients with Subarachnoid Hemorrhage, Neurocrit Care, 2008;9(2):198-203. DOI: 10.1007/s12028-008-9113-8

38. Dignass A. Farrag K. Stein J. Limitations of Serum Ferritin in Diagnosing Iron Deficiency in Inflammatory Conditions. Int J Chronic Dis. 2018;2018:9394060. DOI: $10.1155 / 2018 / 9394060$ 